\title{
HIGH-TEMPERATURE RELIABILITY OF GaN ELECTRONIC DEVICES
}

\author{
Seikoh Yoshida and Joe Suzuki \\ Yokohama R\&D Laboratories, The Furukawa Electric Co., Ltd. \\ 2-4-3, Okano, Nishi-ku, Yokohama, 220-0073, Japan, seikoh@ yokoken.furukawa.co.jp
}

\begin{abstract}
High-quality GaN was grown using gas-source molecular-beam epitaxy (GSMBE). The mobility of undoped $\mathrm{GaN}$ was $350 \mathrm{~cm}^{2} / \mathrm{Vsec}$ and the carrier concentration was $6 \times 10^{16} \mathrm{~cm}^{-3}$ at room temperature. A GaN metal semiconductor field-effect transistor (MESFET) and an n-p-n GaN bipolar junction transistor (BJT) were fabricated for hightemperature operation. The high-temperature reliability of the GaN MESFET was also investigated. That is, the lifetime of the FET at $673 \mathrm{~K}$ was examined by continuous current injection at $673 \mathrm{~K}$. We confirmed that the FET performance did not change at $673 \mathrm{~K}$ for over $1010 \mathrm{~h}$. The aging performance of the BJT at $573 \mathrm{~K}$ was examined during continuous current injection at $573 \mathrm{~K}$ for over $850 \mathrm{~h}$. The BJT performance did not change at $573 \mathrm{~K}$. The current gain was about 10 . No degradation of the metalsemiconductor interface was observed by secondary ion-mass spectrometry (SIMS) and transmission electron microscopy (TEM). It was also confirmed by using Si-ion implantation that the contact resistivity of the GaN surface and electrode materials could be lowered to $7 \times 10^{-6} \mathrm{ohmcm}^{2}$.
\end{abstract}

\section{INTRODUCTION}

III-V nitrides, SiC and diamond, are very promising materials for electronic devices that can operate under high-temperature, high-power, and high-frequency conditions [1], since these materials have a high melting point, a wide bandgap, a high breakdown electric field, and a high saturation velocity [2]. Furthermore, they have very low onresistance during operation compared with Si devices. Several groups have reported on GaN electronic devices [3-5]. Regarding high-temperature operation devices, there have only been a few reports concerning transistors that can operate at temperatures of $673 \mathrm{~K}$ [3-7], and the reliability of the GaN metal semiconductor field effect transistor (MESFET) at high-temperature. We have recently investigated the GaN MESFET using gas-source molecular beam epitaxy (GSMBE) [8-11]. However, until now, no life test of the FET by continuous current-injection at $673 \mathrm{~K}$ for over $1010 \mathrm{~h}$ has been reported.

Furthermore, there have been few reports concerning the bipolar junction transistor [12-15]. Pankov fabricated a hetero-bipolar junction transistor using n-type GaN and ptype $\mathrm{SiC}$, since p-type $\mathrm{GaN}$ with a high carrier concentration was very difficult to grow. They obtained a high current gain and high-temperature operation at $533 \mathrm{~K}$. We have also recently reported that a $\mathrm{GaN} n-\mathrm{p}-\mathrm{n}$ bipolar junction transistor can be operated at high temperature [15]. However, life test at $573 \mathrm{~K}$ for over $800 \mathrm{~h}$ has not been reported.

This paper reports on the high-temperature reliability concerning a life test of a GaN MESFET at $673 \mathrm{~K}$ for over $1010 \mathrm{~h}$, a life test of over $850 \mathrm{~h}$ at $623 \mathrm{~K}$ of an n-p-n bipolar junction transistor and $\mathrm{Si}$-ion implantation technique for obtaing a low-contact resistivity.

\section{EXPERIMENT PROCEDURE}


A GSMBE apparatus was described elsewhere [8]. Dimethylhydrazine (DMHy, $\left.\left(\left(\mathrm{CH}_{3}\right)_{2} \mathrm{NNH}_{2}\right)\right)$ as a nitrogen source gas, and ammonia $\left(\mathrm{NH}_{3}\right)$ as a nitrogen source gas, as well as Knudsen effusion cells for a solid $\mathrm{Ga}$ source, $\mathrm{Si}$ as an n-type dopant, and $\mathrm{Mg}$ as a p-type dopant were also placed in this chamber. The buffer layers of $\mathrm{GaN}$ were grown using DMHy at substrate temperatures of $973 \mathrm{~K}$, since DMHy was easily decomposed at lower temperatures (below $873 \mathrm{~K}$ ) compared to that of ammonia. The $\mathrm{Ga}$ beam-equivalent pressure (BEP) was $5 \times 10^{-7}$ Torr and the BEP of DMHy was $4 \times 10^{-5}$

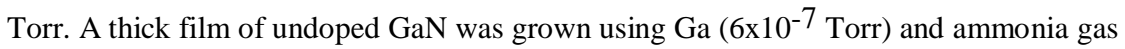
$\left(5 \times 10^{-6}\right.$ Torr) on the GaN buffer layer at $1123 \mathrm{~K}$. The BEP of Si was $5 \times 10^{-9}$ Torr and that of $\mathrm{Mg}$ was $8 \times 10^{-9}$ Torr. The growth rate was $500 \mathrm{~nm} / \mathrm{h}$. The carrier concentration of undoped $\mathrm{GaN}$ grown at $1123 \mathrm{~K}$ was $6 \times 10^{16} \mathrm{~cm}^{-3}$ and the mobility was 350 $\mathrm{cm}^{2} / \mathrm{Vsec}$. The carrier concentration of Mg-doped GaN was $2 \sim 3 \times 10^{17} \mathrm{~cm}^{-3}$ (p-type) and the mobility was about $20 \sim 30 \mathrm{~cm}^{2} / \mathrm{Vsec}$ at room temperature. The activation ratio of $\mathrm{Mg}$ was smaller than $10^{-2}$ compared with the results of a secondary-ion massspectrometry (SIMS) analysis. In the case of Si doping, the n-type carrier concentration was controlled in the range from $1 \times 10^{17} \mathrm{~cm}^{-3}$ to $5 \times 10^{18} \mathrm{~cm}^{-3}$. An etching technique using an electron cyclotron resonance (ECR) plasma was used for $\mathrm{GaN}$ device fabrications. Si ion implantation into $\mathrm{GaN}$ was carried out to obtain a lower contact resistivity. The structures of the MESFET and the bipolar junction transistor were made using GaNs grown by GSMBE.

\section{RESULTS AND DISCUSSION}

\section{$\underline{\text { Si-ion implantation }}$}

The GaN surface layer with a Si concentration of over $10^{19} \mathrm{~cm}^{-3}$ is very important to obtain a very lower n-type contact resistivity. When we doped the Si with a carrier concentration of over $10^{19} \mathrm{~cm}^{-3}$ into the GaN layer using GSMBE, the surface morphology of $\mathrm{GaN}$ was very rough, and sometimes $\mathrm{Si}$ precipitates were observed on the grown GaN surface. Furthermore, when we formed an n-type ohmic electrode, the contact resistivity between the electrode materials and the GaN was very high. In our growth system, a high Si doping of over $10^{19} \mathrm{~cm}^{-3}$ into the GaN layer was very difficult. In order to reduce the contact resistivity, we investigated $\mathrm{Si}$ ion implantation instead of high Si doping based on growth. The Si-ion implantation acceleration voltage was $30 \mathrm{keV}$. The amount of Si dose was $1 \times 10^{19} \mathrm{~cm}^{-3}$. The depth of Si ion implantation was $10 \sim 30 \mathrm{~nm}$. The substrate was heated at $873 \mathrm{~K}$ during Si-ion implantation. After ion implantation, GaN was annealed at $1123 \mathrm{~K}$ for $30 \mathrm{~min}$ an the ambient of nitrogen gas. Undoped GaN was used for implantation.

The sheet resistivity of undoped $\mathrm{GaN}$ without was $350 \mathrm{ohm} / \mathrm{cm}^{2}$. After implantation, the sheet resistivity was reduced to $25 \mathrm{ohm} / \mathrm{cm}^{2}$. Furthermore, the contact resistivity between the electrode materials and the $\mathrm{GaN}$ surface was measured. The $\mathrm{n}$ - 


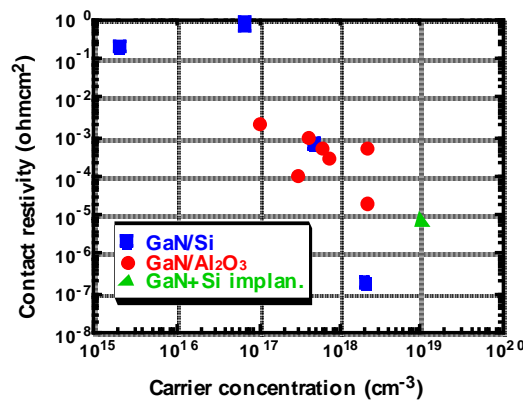

Figure 1. Contact resistivities versus $\mathrm{GaN}$ carrier concentrations.

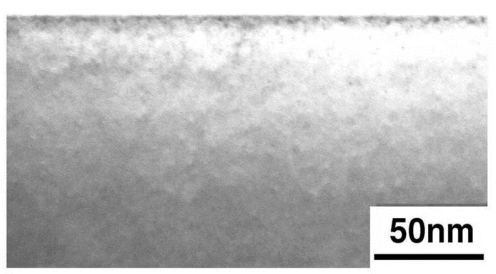

Figure 2. Cross-sectional TEM image of $\mathrm{GaN}$ after Si-ion implantation and annealing at $1123 \mathrm{~K}$.

type ohmic electrode material was $\mathrm{Al} / \mathrm{Ti} / \mathrm{Au}(30 \mathrm{~nm} / 100 \mathrm{~nm} / 50 \mathrm{~nm})$. Before ion implantation, the contact resistivity of the undoped $\mathrm{GaN}$ was $3 \times 10^{-3} \mathrm{ohmcm}^{2}$. After Siion implantation, the contact was $7 \times 10^{-6} \mathrm{ohmcm}^{2}$ as shown in Figure 1. That is, it was confirmed that $\mathrm{Si}$-ion implantation into the $\mathrm{GaN}$ layer was very effective for reducing the contact resistivity. Furthermore the cross-seat ion of Si-implanted GaN was observed by transmission electron microscopy (TEM). Figure 2 shows a TEM image of Siimplanted GaN after annealing at $1123 \mathrm{~K}$. No damage based on Si-ion implantation was observed. Therefore, it was thus confirmed that Si-ion implantation is very effective for the contact resistivity.

\section{GaN MESFET}

The GaN MESFET structure is as follows [14]. A 50 nm-thick GaN buffer layer was grown on a sapphire substrate. An undoped $1000 \mathrm{~nm}$-thick GaN layer was grown on an GaN buffer layer and an AlN layer was grown on the undoped GaN layer to isolate the active layer. Lastly, a $350 \mathrm{~nm}$-thick Si-doped $\mathrm{GaN}$ active layer was grown on the AlN layer. The surface morphology of the grown GaN was smooth. The active layer had a carrier concentration of $3 \times 10^{17} \mathrm{~cm}^{-3}$ and a mobility of $250 \mathrm{~cm}^{2} / \mathrm{Vsec}$ at room temperature. Etching of the $\mathrm{GaN}$ was carried out by a dry-etching technique using an ECR plasma to form the FET. The etching gas was a mixture of $\mathrm{CH}_{4}(5 \mathrm{sccm}), \mathrm{Ar}$ (7 $\mathrm{sccm}$ ), and $\mathrm{H}_{2}$ (15 sccm) [10]. The etching rate of the Si-doped and undoped GaN layers was $14 \mathrm{~nm} / \mathrm{min}$. We formed a source and drain using Au/Ti/Al, and a Schottky-gate as $\mathrm{Au} / \mathrm{Pt}$ on a patterned GaN sample using an ECR sputter-evaporation method, respectively. The gate length of the GaN MESFET was $2.5 \mu \mathrm{m}$ and the gate width was $100 \mu \mathrm{m}$.

The FET property was obtained at room temperature. The breakdown voltage between gate-source was also about $80 \mathrm{~V}$. The pinch-off voltage was about $-8 \mathrm{~V}$. The transconductanse $\left(\mathrm{g}_{\mathrm{m}}\right)$ was about $25 \mathrm{mS} / \mathrm{mm}$. Furthermore, to investigate the hightemperature reliability of a GaN MESFET, we carried out a life test of a FET by continuous current-injection at $673 \mathrm{~K}$. The FET property at $673 \mathrm{~K}$ was measured by continuously injecting a current of $\mathrm{I}_{\mathrm{ds}}$ at $\mathrm{V}_{\mathrm{ds}}=20 \mathrm{~V}$ and $\mathrm{V}_{\mathrm{gs}}=0 \mathrm{~V}$. Figure 3 shows the aging time versus $\mathrm{I}_{\mathrm{ds}}$ of GaN MESFET at $673 \mathrm{~K}$. It should be noted that no change of $\mathrm{I}_{\mathrm{ds}}$ was observed for over $1010 \mathrm{~h}$. The $\mathrm{g}_{\mathrm{m}}$ was also constant at $25 \mathrm{mS} / \mathrm{mm}$. Figure 4 shows the characteristics of $\mathrm{I}_{\mathrm{ds}}$ as a function of $\mathrm{V}_{\mathrm{ds}}$ for increasing values of the gatesource voltage $\left(\mathrm{V}_{\mathrm{gs}}\right)$ at $673 \mathrm{~K}$. The pinch-off voltage was also about $-8 \mathrm{~V}$. The FET 


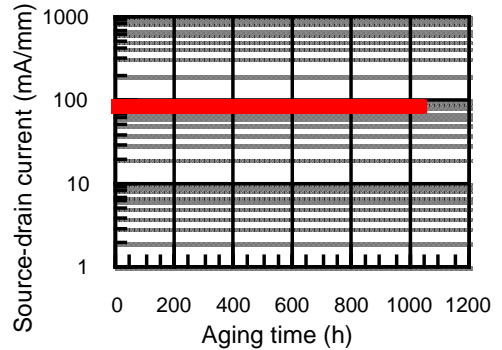

Figure 3. Aging property of $\mathrm{I}_{\mathrm{ds}}$ of a GaN MESFET during continuouscurrent injection at $673 \mathrm{~K}$.

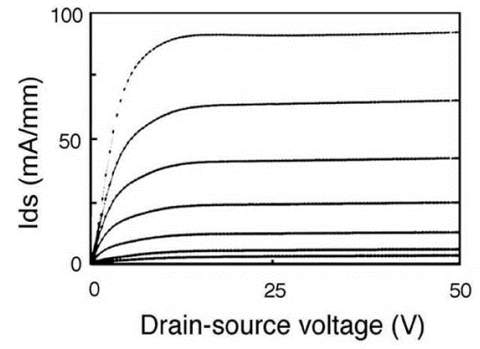

Figure 4. Current-voltage characteristics $\left(\mathrm{I}_{\mathrm{ds}}-\mathrm{V}_{\mathrm{ds}}\right)$ of a GaN MESFET at $673 \mathrm{~K}$.

The gate voltages $\left(\mathrm{V}_{\mathrm{gs}}\right)$ was changed from $0 \mathrm{~V}$ to $-5 \mathrm{~V}$ in steps of $-1 \mathrm{~V}$.

property was almost the same as that at room temperature, and good performance of the FET was maintained at $673 \mathrm{~K}$. Using transmission electron microscopy (TEM), we also observed that the interfaces of the electrode materials and the GaN layer were not degraded.

Based on these results, the high-temperature reliability of a GaN MESFET was confirmed, since the electrode materials did not diffuse into the $\mathrm{GaN}$, and the GaN layer was not deformed at $673 \mathrm{~K}$.

\section{$\underline{\text { GaN bipolar junction transistor }}$}

We investigated the reliability of a GaN bipolar junction transistor (BJT) at high temperature. The structure of the bipolar junction transistor using $\mathrm{GaN}$ is shown in Figure 5 The thicknesses of the emitter, base, and collector layers were $450 \mathrm{~nm}, 350 \mathrm{~nm}$, and $500 \mathrm{~nm}$, respectively. The carrier concentration of the emitter and collector was $5 \times 10^{17} \mathrm{~cm}^{-3}$ and the base carrier concentration was $1.5 \times 10^{17} \mathrm{~cm}^{-3}$. The structure was also formed by ECR plasma etching using $\mathrm{CH}_{3} / \mathrm{Ar} / \mathrm{H}_{2}$. The emitter size was 350x400

$\mu \mathrm{m}^{2}$. The sizes of the base and collector were $200 \times 150 \mu \mathrm{m}^{2}$ and $450 \times 600 \mu \mathrm{m}^{2}$, respectively. The electrode materials of the emitter and collector were formed using $\mathrm{Au} / \mathrm{Ti} / \mathrm{Al}$. The base contact was also formed using $\mathrm{Au} / \mathrm{Ti} / \mathrm{Ni}$.

In order to investigate the operation of the bipolar junction transistor at $573 \mathrm{~K}$, the current-voltage characteristics, as measured in the common emitter mode at $573 \mathrm{~K}$, were measured. It was found that the bipolar junction transistor performance at $573 \mathrm{~K}$ remained unchanged, as shown in Figure 6, although $\mathrm{I}_{\mathrm{c}}$ was slightly changed compared with that produced at room temperature. The current gain $\left(\mathrm{dI}_{\mathrm{C}} / \mathrm{dI}_{\mathrm{b}}\right)$ was about 10 . Figure 7 shows the p-n junction property between the base and the emitter electrodes during heating at $573 \mathrm{~K}$. The breakdown voltage was over $10 \mathrm{~V}$. Furthermore, a life test of a bipolar junction transistor was carried out. Figure 8 shows the result of an aging test at $573 \mathrm{~K}$. Here, $\mathrm{V}_{\mathrm{c}}$ was $4 \mathrm{~V}$ and $\mathrm{I}_{\mathrm{b}}$ was $120 \mu \mathrm{A}$. Ic did not change for over $850 \mathrm{~h}$. That is, it was confirmed that the bipolar junction transistor was operated for over $850 \mathrm{~h}$. It was also found by SIMS that interfaces between the electrode materials and the GaN layer after heating at $573 \mathrm{~K}$ was abrupt and that the GaN was not affected by heating at 573 $\mathrm{K}$. We thus confirmed the reliability of the GaN bipolar junction transistor at $573 \mathrm{~K}$. 


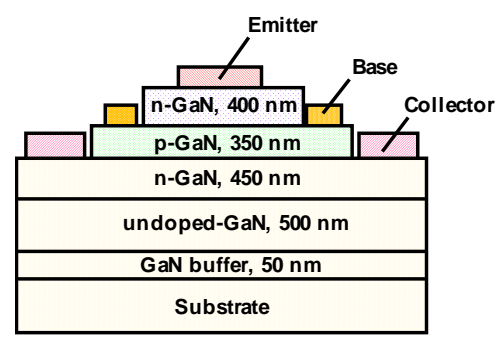

Figure 5. Schematic drawing of the structure of an n-p-n bipolar junction transistor using a GaN.

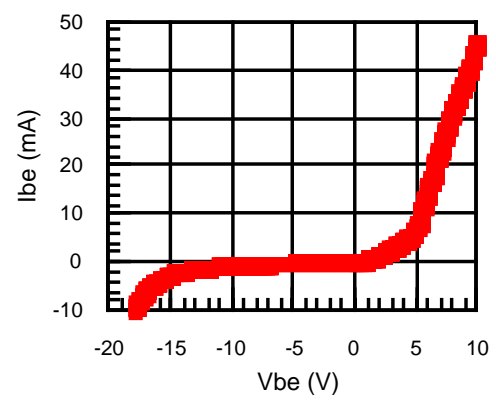

Figure 7. p-n junction property between of the base and emitter electrodes at $573 \mathrm{~K}$.

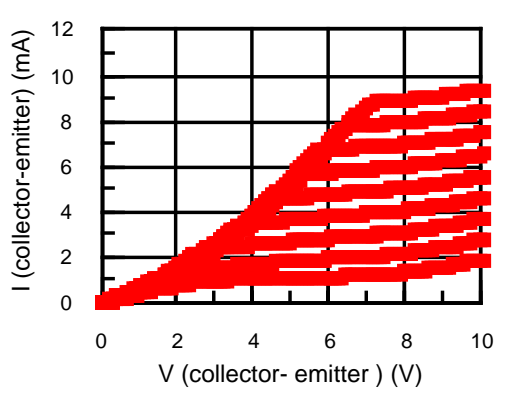

Figure 6. Current $\left(\mathrm{I}_{\mathrm{c}}\right)$ - voltage $\left(\mathrm{V}_{\mathrm{c}}\right)$ characteristics as measured in the common-emitter mode at $573 \mathrm{~K}$.

The base current $\left(\mathrm{I}_{\mathrm{b}}\right)$ was changed from $20 \mu \mathrm{A}$ in steps of $50 \mu \mathrm{A}$.

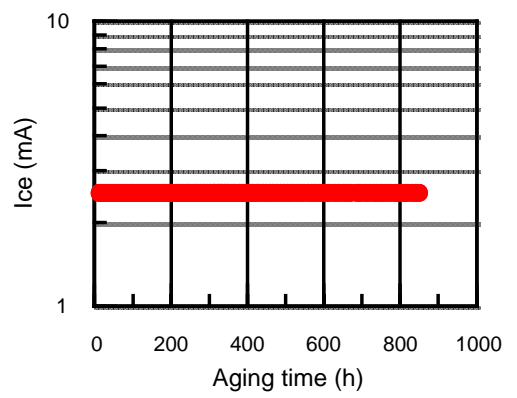

Figure 8. Aging property of $\mathrm{GaN}$ BJT at $573 \mathrm{~K}$.

\section{CONCLUSION}

A high-quality GaN was grown using GSMBE. A GaN MESFET and an n-p-n bipolar junction transistor were fabricated. The life test of a GaN MESFET at $673 \mathrm{~K}$ was examined by continuous current-injection at $673 \mathrm{~K}$. We confirmed that the FET performance did not change at $673 \mathrm{~K}$ for over $1010 \mathrm{~h}$. No degradation of the metalsemiconductor interface was observed by SIMS or TEM. Furthermore, the fabrication of a GaN bipolar junction transistor was carried out. The life performance of the bipolar transistor at $573 \mathrm{~K}$ was examined during continuous current-injection at $573 \mathrm{~K}$. We confirmed that the performance of the bipolar transistor did not change at $573 \mathrm{~K}$ for over 850 h. No degradation of the metal-semiconductor interface was observed by SIMS or TEM. The reliability of a GaN BJT at high temperature was thus confirmed.

\section{REFERENCES}


1. T. P. Chow and R. Tyagi, IEEE Trans. Electron Devices 41, 1481 (1994).

2. H. Morkoc, S. Strites, G. B. Gao, M. E. Lin, B. Sverdlov and M. Burns, J. Appl. Phys. 76, 1363 (1994).

3. S. C. Binari, B. L. Rowland, W. Kruppa, G. Kelner, K. Doverspike, and D. K. Gaskill, Electron. 30, 1248 (1994).

4. M. A. Khan, M. S. Shur, J. N. Kuzunia, Q. Chin, J. Burm and W. Schaff, Appl. Phys. 66, 1083 (1995).

5. A. Ozgur, W. Kim, Z. Fan, A. Botchkarev, A. Salvador, S. N. Mohammad, B. Sverdlov and H. Morko , Electron. 31, 1389 (1995).

6. O. Akutas, Z. F. Fan, S. N. Mohammad, A. E. Botchkarev and H. Morko , Appl. Phys. 69, 3872 (1996).

7. S. C. Binari, K. Doverspike, G. Kelner, H. B. Dietrich and A. E. Wickenden, Solid State Electron. 41, 97 (1997).

8. S. Yoshida, J. Appl. Phys. 81, 1673 (1997).

9. S. Yoshida, J. Cryst. Growth, 181, 293 (1997).

10. S. Yoshida and J. Suzuki, Jpn. J. Appl. Phys. 37, L482 (1998).

11. S. Yoshida and J. Suzuki, J. Appl. Phys. 84, 2940 (1998).

12. J. Pankov, S. S. Chang, H. C. Lee, R. J. Molnar, T. D. Moustakas and B. Van Zeghbroeck, IEDM Tech. Dig., 389 (1994).

13. L. S. Mc Carthy, P. Kozodoy, M. J. W. Rodwell, S. P. Denbaars and U. K. Mishra, IEEE Electron Device. Lett. 20, 277 (1998).

14. S. Yoshida and J. Suzuki, J.Appl. Phys. 85, 7931 (1999).

15. S. Yoshida and J. Suzuki, Jpn. J. Appl. Phys. 38, L851 (1999). 